\title{
Downregulation of transgelin 2 promotes breast cancer metastasis by activating the reactive oxygen species/nuclear factor- $\kappa \mathrm{B}$ signaling pathway
}

\author{
LIU YANG $^{1,2^{*}}$, QI HONG ${ }^{1,3^{*}}$, SI-GUANG XU ${ }^{1}$, XIA-YING KUANG ${ }^{4}$, GEN-HONG DI $^{1,2}$, \\ GUANG-YU LIU ${ }^{1,2}$, JIONG WU ${ }^{1,2}$, ZHI-MING SHAO ${ }^{1-3}$ and SAN-JIAN YU ${ }^{1}$ \\ ${ }^{1}$ Department of Breast Surgery, Key Laboratory of Breast Cancer in Shanghai, \\ Fudan University Shanghai Cancer Center; ${ }^{2}$ Department of Oncology, Shanghai Medical College; \\ ${ }^{3}$ Institutes of Biomedical Science, Fudan University, Shanghai 200032; ${ }^{4}$ Department of Breast Surgery, \\ The First Affiliated Hospital, Sun Yat-Sen University, Guangzhou, Guangdong 510080, P.R. China
}

Received December 20, 2018; Accepted July 17, 2019

DOI: $10.3892 / \mathrm{mmr} .2019 .10643$

\begin{abstract}
Transgelin 2 (TAGLN2) is a cytoskeletal protein of the calponin family. Abnormal expression of TAGLN2 was observed in various types of cancer. Our previous study reported that TAGLN2 expression was reduced in lymph node-positive breast cancer patients; however, the role of TAGLN2 in breast cancer metastasis remains unknown. In the present study, the role of TAGLN2 in breast cancer metastasis was investigated in vitro and in vivo via Transwell migration, luciferase and flow cytometry assays, and a mouse xenograft model. Proteins interacting with TAGLN2 were identified via co-immunoprecipitation assays and liquid chromatography/mass spectrometry, and the signaling pathway associated with the effects of TAGLN2 was investigated. Additionally, western blotting and reverse transcription-quantitative polymerase chain reaction were performed to further explore the potential pathway in which TAGLN2 may be involved and the mechanism underlying its effects in breast cancer metastasis. The present study reported that TAGLN2 expression was increased by 11.4 -fold in patients without distant
\end{abstract}

Correspondence to: Dr San-Jian Yu or Professor Zhi-Ming Shao, Department of Breast Surgery, Key Laboratory of Breast Cancer in Shanghai, Fudan University Shanghai Cancer Center, Fudan University, 270 Dong An Road, Shanghai 200032, P.R. China

E-mail: yusanjian@outlook.com

E-mail: zhimingshao@yahoo.com

*Contributed equally

Abbreviations: TAGLN2, transgelin 2; PRDX1, peroxiredoxin 1; ROS, reactive oxygen species; ER, estrogen receptor; PR, progesterone receptor; HER2, human epidermal growth factor receptor 2

Key words: metastasis, breast cancer, PRDX1, ROS, nuclear factor- $\kappa \mathrm{B}$ pathway metastasis compared with those positive for distant metastasis. Knockdown of TAGLN2 resulted in increased cell migration in vitro and promoted lung metastasis in vivo. Additionally, overexpression of TAGLN2 suppressed lung metastasis in a mouse model. Peroxiredoxin 1 (PRDX1), an important reactive oxygen species (ROS) regulator, was revealed to interact with TAGLN2. In addition, mitochondrial redistribution and PRDX1 downregulation were reported following TAGLN2 silencing, which promoted ROS production and nuclear factor (NF)- $\mathrm{\kappa B}$ activation in breast cancer cells. This induced the expression of metastasis-associated genes, including C-X-C chemokine receptor 4, matrix metalloproteinase (MMP) 1 and MMP2. The present study proposed TAGLN2 to function as a tumor suppressor and that loss of TAGLN2 may promote the metastasis of breast cancer by activating the ROS/NF- $\mathrm{\kappa B}$ signaling pathway.

\section{Introduction}

Notable developments have been made in the systemic therapy and early diagnosis of breast cancer; however, this disease remains to be the second leading cause of cancer-associated mortality in females $(1,2)$. Distant metastasis represents as the major cause of mortality in patients with breast cancer (3). Metastasis is a multistep process characterized by the progressive accumulation of genetic alterations that results in aberrant cell growth, malignant transformation, vascular invasion and ultimately, metastasis (4-5). Gene expression and proteomics analyses have revealed several novel metastasis-associated factors underlying the development and progression of breast cancer (6-11); however, the role of these factors requires further investigation, yet metastasis remains a serious problem in the treatment of this disease.

Transgelin 2 (TAGLN2) is a $22-\mathrm{kDa}$ protein and one of the earliest markers of differentiated smooth muscle (12). TAGLN2 belongs to the calponin family of proteins as it contains an N-terminal calponin homology domain and a C-terminal calponin-like domain (13). TAGLN2 binds to actin to facilitate the formation of cytoskeletal structures, such as 
stress fibers (14). The dysregulated expression of TAGLN2 has been observed in various types of cancer (7,15-18). A previous study indicated that TAGLN2 inhibited the motility of hepatocarcinoma cells by suppressing actin polymerization (16). In endometrial and ovarian cancers, TAGLN2 was downregulated in metastatic tumors compared with primary tumors (17). Downregulated TAGLN2 expression has been reported to be a prognostic indicator for shorter disease-free survival in Barrett's adenocarcinoma (15). A notable correlation was observed between reduced TAGLN2 expression and regional lymph node metastasis.

Reactive oxygen species (ROS) serve important roles in the migration and invasion of cancer cells (19-23). The stimulation of cell surface receptors with growth factors and integrin induces the production of ROS. The dynamic nature of actin and mitochondrial dysfunction have been associated with ROS production (24). ROS act within cells to activate downstream signaling pathways, including the nuclear factor- $\kappa \mathrm{B}$ $(\mathrm{NF}-\mathrm{\kappa B})$, and signaling transducer and activator of transcription 3 pathways that promote migration and invasion (25-29). Peroxiredoxin 1 (PRDX1) belongs to the peroxiredoxin family of antioxidant enzymes, which serve an important role in the maintenance of intracellular ROS levels (30-32). The reduced expression of PRDX1 results in decreased total antioxidant capacity, inducing ROS production (33). In breast cancer, PRDX1 functions as a specific sensor in redox-regulated senescence; silencing of PRDX1 increased the susceptibility for developing Ras-induced breast cancer (34). Thus, the dysfunction of PRDX1 may contribute to the progression of breast cancer.

Our previous results from differential proteomics and immunohistochemical analyses revealed that TAGLN2 was downregulated in MDA-MB-231HM cells, which has a high metastatic potential (7). Additionally, immunohistochemical analysis demonstrated that the expression of TAGLN2 was suppressed in lymph node-positive invasive ductal carcinoma tissues (7). These findings suggested that TAGLN2 may be negatively associated with breast cancer metastasis. Nevertheless, the biological mechanism by which TAGLN2 downregulation induces the metastatic phenotype of breast cancer cells remains unknown.

In the present study, it was demonstrated that TAGLN2 knockdown promoted MDA-MB-231 cell invasion and enhanced lung metastasis in vivo. In addition, TAGLN2 was determined to interact with PRDX1. Knockdown of TAGLN2 resulted in reduced PRDX1 expression, elevated ROS levels, mitochondrial redistribution and the activation of the $\mathrm{NF}-\kappa \mathrm{B}$ pathway, which led to the induction of metastasis-associated genes, including $\mathrm{C}-\mathrm{X}-\mathrm{C}$ chemokine receptor 4 (CXCR4), matrix metalloproteinase (MMP)1 and MMP2. The results of the present study suggest that loss of TAGLN2 expression may promote tumor invasion via ROS and the NF- $\mathrm{NB}$ pathway, PRDX1 downregulation and redistribution of the mitochondria.

\section{Materials and methods}

Cell lines and breast tumor specimens. A panel of breast cancer cell lines were obtained from the American Type Culture Collection in June 2015, including BT-549, MDA-MB-231 and
MCF-7. The 293T cell line was obtained from the Cell Bank of China in 2015 and maintained in Dulbecco's modified Eagles medium (Gibco; Thermo Fisher Scientific, Inc.) containing 10\% fetal bovine serum (Gibco; Thermo Fisher Scientific, Inc.), $100 \mathrm{U} / \mathrm{ml}$ penicillin and $100 \mu \mathrm{g} / \mathrm{ml}$ streptomycin (Invitrogen; Thermo Fisher Scientific, Inc.). Cell lines underwent DNA profiling of short tandem repeats in our laboratory in 2016. The cell lines were subjected to routine cell line quality examination, via morphological analysis and mycoplasma testing by HD Biosciences every 3 months until used in the present study. Frozen aliquots were stored in liquid nitrogen; cells were cultured for $\leq 6$ months after thawing. All human breast cancers specimens were randomly obtained from patients aged 27-79 years old with pathologically confirmed stage I-III primary breast cancer with no distant metastasis; patients underwent surgery for breast cancer between March 2003 and December 2009 at the Fudan University Shanghai Cancer Center. The specimens were stored in liquid nitrogen until analysis. All specimens contained $>90 \%$ tumor cells. All patients provided written informed consent. The study complied with the Declaration of Helsinki and was approved by the Ethics Committee of the Fudan University Shanghai Cancer Center.

Breast cancer subtypes were categorized as luminal, or based on human epidermal growth factor receptor 2 (HER2)-positive and triple negative according to the available estrogen receptor, progesterone receptor and HER 2 status. TNM stage and T stage were defined according to the 6th American Joint Committee on Cancer (AJCC) TNM staging system, which include the status of tumor, lymph node and metastasis (35).

Small interfering (si)RNA, plasmid construction, transfection and luciferase assays. Specific siRNAs and negative controls (scrambled siRNA) were purchased from Shanghai GenePharma Co., Ltd. Cells cultured in 6-well plates were transfected with $100 \mathrm{pmol} /$ well siRNA using Hilymax Transfection Agent (Dojindo Molecular Technologies, Inc.) according to the manufacturer's protocols. Scrambled siRNAs comprised random sequences with no detectable effects in human cell lines. Short hairpin (sh)RNAs were obtained from the RNAi Consortium (https://www. broadinstitute.org/scientific-community/science/projects/rnaiconsortium/rnai-consortium). pLKO-shRNA vector was purchased from Addgene, Inc. (cat. no. 30,323). Green fluorescent protein-specific shRNAs were used as unrelated negative controls. The sequences of the siRNAs, shRNA and negative controls are listed in Table I. The vector pGL4.32 containing $\mathrm{NF}-\kappa \mathrm{B}$ transcription responsive elements (TREs) was from Promega Corporation (cat. no. E849A).

The coding DNA sequence of human TAGLN2 was cloned into the EcoRI/NotI sites of the pCDH vector (Systembio). The clone primer sequences were listed in Table I. For the luciferase assays, 293T-pGL4.32 cells were plated in 6-well plates and transfected with $100 \mathrm{pmol} /$ well of the siRNA or a negative control. The luciferase plasmid was purchased from Beyotime Institute of Biotechnology. The luciferase activity was normalized to that of Renilla. The Bright-Glo ${ }^{\mathrm{TM}}$ Luciferase Assay System was used to analyze luciferase activity $48 \mathrm{~h}$ post-transfection.

Protein extraction and western blot analysis. Cells were lysed in SDS cell lysis buffer containing $50 \mathrm{mM}$ Tris ( $\mathrm{pH} 8.1)$ 
Table I. Sequences of primers, siRNA and shRNAs.

\begin{tabular}{|c|c|c|}
\hline Purposes & Sequence type & Sequence $\left(5^{\prime}-3^{\prime}\right)$ \\
\hline \multirow[t]{2}{*}{ TAGLN2 clone primer } & Sense & GTCAGTGCGCTGCTCTCC \\
\hline & Antisense & CCCTGACAGAAAGGAGCTTG \\
\hline \multirow[t]{2}{*}{ TAGLN2 FLAG clone primer } & Sense & GCGAAGCTTGCCAACAGGGGACCTGC \\
\hline & Antisense & AGAATTCTCAGAGGATCTGGCGTGGC \\
\hline \multirow[t]{4}{*}{ TAGLN2 shRNA 586} & Top & CCGGGAACGTGATCGGGTTACAGATCTCGAGATCTG \\
\hline & & TAACCCGATCACGTTCTTTTTTG \\
\hline & Bottom & aattCAAAAAAGAACGTGATCGGGTTACAGATCTCGA \\
\hline & & GATCTGTAACCCGATCACGTTC \\
\hline \multirow[t]{4}{*}{ TAGLN2 shRNA 377} & Top & CCGGCGCTATGGCATTAACACCACTCTCGAGAGTGG \\
\hline & & TGTTAATGCCATAGCGTTTTTTG \\
\hline & Bottom & aattCAAAAAACGCTATGGCATTAACACCAC TCTCGAG \\
\hline & & AGTGGTGTTAATGCCATAGCG \\
\hline \multirow[t]{4}{*}{ TAGLN2 shRNA 252} & Top & CCGGCGGTGCTATGTGAGCTCATTACTCGAGTAATGA \\
\hline & & GCTCACATAGCACCGTTTTTTG \\
\hline & Bottom & aattCAAAAAACGGTGCTATGTGAGCTCATTACTCGAG \\
\hline & & TAATGAGCTCACATAGCACCG \\
\hline siRNA TAGLN2 252 & Target & CGACCAATAGCTCAGATCCTT \\
\hline siRNA TAGLN2 377 & Target & CAGGTGATACTATCAACCAAA \\
\hline siRNA negative control & & GUGGAUAUUGUUGCCAUCA \\
\hline
\end{tabular}

shRNA, short hairpin RNA; siRNA, small interfering RNA; TAGLN2, transgelin 2. The lowercase letters represent restriction endonuclease site of EcoRI.

and $1 \%$ SDS, supplemented with protease inhibitors (Roche Diagnostics) for $30 \mathrm{~min}$ on ice. The homogenates were centrifuged at $18,000 \mathrm{x} \mathrm{g}$ for $10 \mathrm{~min}$ at $4^{\circ} \mathrm{C}$. Supernatants were collected, and the protein concentration was determined by a Bradford's assay (Bio-Rad Laboratories, Inc.); $30 \mu \mathrm{g}$ of the proteins was loaded for analysis. The proteins were separated via $10 \%$ SDS-PAGE and transferred to polyvinylidene fluoride membranes (EMD Millipore). The membranes were probed with primary antibodies against PRDX1 (1:1,000; cat. no. EPR5433; Epitomics, Abcam, Cambridge, UK), FLAG (1:500; cat.no.F7425; Sigma-Aldrich,Merck KGaA), TAGLN2 (1:1,000; cat. no. 60044-1-lg; ProteinTech Group, Inc.), IкB (1:3,000; cat. no. 66418-1-lg; ProteinTech Group, Inc.), p50 (1:200; cat. no. 15506-1-AP; ProteinTech Group, Inc.), p65 (1:1,000; cat. no 10745-1-AP; ProteinTech Group, Inc.), MMP1 (1:1,000; cat. no. 54376; Cell Signaling Technology), MMP2 (1:1,000; cat. no. 4022; Cell Signaling Technology), CXCR4 (1:1,000; cat. no. ab181020; Abcam, Cambridge, UK), Lamin B1 (1:3,000; cat. no. 12987-1-AP; ProteinTech Group, Inc.) and GAPDH (1:3,000; cat. no. 60004-1-1g; ProteinTech Group, Inc.) on the rocking table at $4^{\circ} \mathrm{C}$ overnight. After washing, the membranes were incubated with appropriate horseradish peroxidase-conjugated secondary antibodies at room temperature for $60 \mathrm{~min}$ : Goat anti-Rabbit IgG (1:3,000; SA00001-2; ProteinTech Group, Inc.), Goat anti-Mouse IgG (1:3,000; SA00001-1; ProteinTech Group, Inc.). The bands were developed via enhanced chemiluminescence (EMD Millipore). Quantity One software version 4.6.2 (Bio-Rad Laboratories, Inc.) was used to quantify protein expression.
Immunoprecipitation. Cells were harvested and lysed in IP buffer (50 mM Tris- $\mathrm{Cl}$ (pH 7.5), $150 \mathrm{mM} \mathrm{NaCl,} 1 \mathrm{mM}$ EDTA, $1 \%$ Triton $\mathrm{X}-100)$ supplemented with proteinase inhibitors $1 \mathrm{mM}$ PMSF, $10 \mu \mathrm{g} / \mathrm{ml}$ aprotonin, $5 \mu \mathrm{g} / \mathrm{ml}$ leupeptin, $0.5 \mu \mathrm{g} / \mathrm{ml}$ pepstatin and $5 \mathrm{mM} \mathrm{NaF}$ on ice for $30 \mathrm{~min}$, centrifuged at $12,000 \mathrm{x}$ for $15 \mathrm{~min}$ at $4^{\circ} \mathrm{C}$ and the supernatants were collected in fresh tube. For immunoprecipitation, $2 \mathrm{mg}$ lysate was incubated and rotated with 20-30 $\mu \mathrm{l}$ Anti-FLAGM2 Magnetic Beads (cat. no. M8823; Sigma-Aldrich; Merck KGaA) or complex of protein A/G magnetic beads (cat. no. B23202; Bimake.com) and primary antibody overnight at $4^{\circ} \mathrm{C}$. The resulting immunoprecipitates were washed at least three times in IP buffer, before boiling with SDS sample buffer. Immunoprecipitated material was analyzed by mass spectrometry and western blotting.

Liquid chromatography/mass spectrometry (LC/MS) and LC/MS-MS platforms for protein identification. LC-MS/MS experiments were performed on LTQ-Orbitrap hybrid mass spectrometer (Thermo Fisher Scientific, Inc.) coupled to a Shimadzu LC-20AD LC system (Shimadzu Corporation) and SIL-20AC autosampler (Shimadzu Corporation). Tryptic peptides were separated by a PICOFRIT C18 reverse-phase column $(0.075 \times 100 \mathrm{~mm}$, New Objective Inc.) at a flow rate of $300 \mathrm{nl} / \mathrm{min}$ with a $110 \mathrm{~min}$-gradient. Each peptide mixture was loaded in solvent $\mathrm{A}\left[95 \% \mathrm{H}_{2} \mathrm{O}, 5 \%\right.$ acetonitrile $(\mathrm{ACN})$, $0.1 \%$ formic acid (FA)] and eluted by $5 \%$ solvent $\mathrm{B}\left(5 \% \mathrm{H}_{2} \mathrm{O}\right.$, $95 \% \mathrm{ACN}, 0.1 \% \mathrm{FA}$ ) for $5 \mathrm{~min}$ followed by a linear gradient to $45 \%$ solvent $\mathrm{B}$ in the next $90 \mathrm{~min}$, then the column was re-equilibrated at initial condition for $15 \mathrm{~min}$. The entire 
eluant was sprayed into the LTQ-Orbitrap mass spectrometer via a dynamic nanospray probe (Thermo Fisher Scientific, Inc.) and analyzed in positive mode. The 3 most abundant precursor ions detected in the full MS survey scan $(\mathrm{m} / \mathrm{z}$ range of 400-2000, $\mathrm{R}=60,000$ ) by Orbitrap were isolated for further MS/MS analyzing in the linear ion trap. The automatic gain control target was set to $1,000,000$ and 10,000 for MS scans and MS/MS scans, respectively. Tandem mass spectra were extracted by Bioworks (version 3.3.1 SP1, Thermo Fisher Scientific,Inc.) and submitted to Human UniProtKB/Swiss-Prot database (Proteome ID: UP000005640, 20199 entries) using TurboSequest v.28 (36) search engine.

ROS detection. Cell suspensions of MDA-MB-231 and MCF-7 were obtained in PBS and flow cytometry was performed. A total of $1 \times 10^{6}$ cells were stained with $2^{\prime}, 7^{\prime}$-dichlorodihydrofluorescein diacetate (DCFDA; $1 \mu \mathrm{M}$ ) at $37^{\circ} \mathrm{C}$ for $30 \mathrm{~min}$ (Thermo Fisher Scientific, Inc.) and then analyzed with a FACSCalibur ${ }^{\mathrm{TM}}$ flow cytometer (BD Biosciences). The percentage of positively-stained cells was quantified using CELLQuest $^{\mathrm{TM}}$ software v5.1 (BD Biosciences).

$R N A$ extraction and reverse transcription-quantitative polymerase chain reaction $(R T-q P C R)$. The tissues were homogenized with Polytron PT100 (Kinematica AG). Total RNA was extracted using TRIzol ${ }^{\circledR}$ (Invitrogen; Thermo Fisher Scientific, Inc.). Total RNA, isolated from cell lines or tissues, was reverse-transcribed using the ReverTra Ace ${ }^{\circledR}$ qPCR RT Kit (Toyobo Life Science). RT was conducted for $15 \mathrm{~min}$ at $42^{\circ} \mathrm{C}$ followed by $5 \mathrm{~min}$ at $98^{\circ} \mathrm{C}$. The mRNA expression levels were quantified by qPCR using the SYBR ${ }^{\circledR}$ Green Real-time PCR Master Mix (Toyobo Life Science). qPCR was performed using an Applied Biosystems 7900HT real-time PCR system, and data were collected and analyzed using ABI SDS version 2.3. The thermocycling conditions were: $95^{\circ} \mathrm{C}$ for $30 \mathrm{sec}$ followed by 40 cycles at $95^{\circ} \mathrm{C}$ for $5 \mathrm{sec}$ and $65^{\circ} \mathrm{C}$ for $30 \mathrm{sec}$. The mRNA expression levels of GAPDH were used as the internal control for gene-specific mRNA analysis. The normalized expression of each sample was designated as the quantification cycle $(\mathrm{Cq})$ and obtained by dividing the $\mathrm{Cq}$ value by the $\mathrm{Cq}$ value of GAPDH of the same sample. The relative amount of mRNA in each sample was calculated using the comparative $\mathrm{Cq}$ method (37). The results are presented as the fold change of expression in cells or cancer tissues. The sequences of primers were listed in Table II.

Invasion assay. The invasive potential of cells was determined by plating 40,000 cells in the upper chamber of Matrigel (BD Biosciences)-coated Transwell invasion chambers according to the manufacturer's instructions. The cells were seeded in DMEM without growth factors; DMEM with $10 \%$ FBS was added to the lower chamber. The cells were incubated in $37^{\circ} \mathrm{C}$ for 24-48 h. The invasive cells were fixed in $95 \%$ ethanol for $20 \mathrm{~min}$, and stained in hematoxylin for $2 \mathrm{~min}$ followed by eosin staining for $1 \mathrm{~min}$ in room temperature. The invasive cells were imaged under a light microscope (magnification, x10) and counted using ImageJ 1.50i software (National Institutes of Health); 5 fields per view were analyzed.

Migration assay. Migration assay was conducted with Transparent PET Membrane 24 well $8.0 \mu \mathrm{m}$ migration insert
Table II. List of primers employed reverse transcriptionquantitative polymerase chain reaction.

\begin{tabular}{|c|c|c|}
\hline Gene & $\begin{array}{l}\text { Sequence } \\
\text { type }\end{array}$ & Sequence $\left(5^{\prime}-3^{\prime}\right)$ \\
\hline \multirow[t]{2}{*}{ TAGLN2 } & Sense & ACCCAGTGCCGAAAGGATG \\
\hline & Antisense & TCAGTGGTGTTAATGCCATAGC \\
\hline \multirow[t]{2}{*}{ VCAM1 } & Sense & GCTGCTCAGATTGGAGACTCA \\
\hline & Antisense & CGCTCAGAGGGCTGTCTATC \\
\hline \multirow[t]{2}{*}{ ICAM1 } & Sense & ATGCCCAGACATCTGTGTCC \\
\hline & Antisense & GGGGTCTCTATGCCCAACAA \\
\hline \multirow[t]{2}{*}{ CX3CL1 } & Sense & ACCACGGTGTGACGAAATG \\
\hline & Antisense & CTCCAAGATGATTGCGCGTTT \\
\hline \multirow[t]{2}{*}{ CCL2 } & Sense & CAGCCAGATGCAATCAATGCC \\
\hline & Antisense & TGGAATCCTGAACCCACTTCT \\
\hline \multirow[t]{2}{*}{ CCR4 } & Sense & ATGAACCCCACGGATATAGCA \\
\hline & Antisense & CACCACAGAATTTCCAAGCAGA \\
\hline \multirow[t]{2}{*}{ CXCR4 } & Sense & TACACCGAGGAAATGGGCTCA \\
\hline & Antisense & AGATGATGGAGTAGATGGTGGG \\
\hline \multirow[t]{2}{*}{ IL6 } & Sense & AACCTGAACCTTCCAAAGATGG \\
\hline & Antisense & TCTGGCTTGTTCCTCACTACT \\
\hline \multirow[t]{2}{*}{ MMP1 } & Sense & ACACATCTGACCTACAGGATTGA \\
\hline & Antisense & GTGTGACATTACTCCAGAGTTGG \\
\hline \multirow[t]{2}{*}{ MMP2 } & Sense & CCCACTGCGGTTTTCTCGAAT \\
\hline & Antisense & CAAAGGGGTATCCATCGCCAT \\
\hline \multirow[t]{2}{*}{ MMP9 } & Sense & TGTACCGCTATGGTTACACTCG \\
\hline & Antisense & GGCAGGGACAGTTGCTTCT \\
\hline \multirow[t]{2}{*}{$\beta$-actin } & Sense & TGACGTGGACATCCGCAAAG \\
\hline & Antisense & CTGGAAGGTGGACAGCGAGG \\
\hline
\end{tabular}

CCL2, chemokine ligand 2; CCR4, C-C motif chemokine receptor 4; CX3CL1, C-X3-C motif chemokine ligand 1; CXCR4, C-XC chemokine receptor type 4; ICAM1, intercellular adhesion molecule 1; IL, interleukin; MMP, matrix metalloproteinase; TAGLN2, transgelin 2; VCAM1, vascular cell adhesion protein 1.

(Falcon; Corning Inc.) by seeding 36,000 cells into the top chamber in DMEM without growth factors and adding DMEM with $10 \%$ FBS to the bottom chamber. The cells were incubated at $37^{\circ} \mathrm{C}$ for $6 \mathrm{~h}$. Cells were stained with $0.1 \%$ Crystal Violet Staining Solution for $30 \mathrm{~min}$ at room temperature and imaged under a light microscope (magnification, x10). The number of migrated cells was counted with ImageJ $1.50 \mathrm{i}$ software (National Institutes of Health) and 5 fields per view were

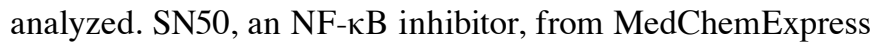
(cat. no. HY-P0151) was dissolved in dimethyl sulfoxide (DMSO). MDA-MB-231 cells transfected with scramble or shTAGLN2 were treated with $18 \mu \mathrm{M}$ SN50 or DMSO for $24 \mathrm{~h}$ before migration assay.

Mitochondrial and F-actin staining. Cells were cultured on coverslips and treated as aforementioned. Cells were fixed in $4 \%$ paraformaldehyde for $10 \mathrm{~min}$ at room temperature prior to permeabilization in PBS containing $0.1 \%$ Triton X-100 for 2 min. MitoTracker Red CMXRos (Thermo Fisher Scientific, Inc.) was used for mitochondrial staining at $37^{\circ} \mathrm{C}$ for $30 \mathrm{~min}$. 
Phalloidin-fluorescein isothiocyanate (Sigma-Aldrich; Merck KGaA) was used for F-actin staining at $37^{\circ} \mathrm{C}$ for $30 \mathrm{~min}$. Cells were rinsed 3 times with PBS and incubated with DAPI ( $1 \mu \mathrm{g} / \mathrm{ml}$; cat. no. 9542; Sigma-Aldrich; Merck KGaA) at $37^{\circ} \mathrm{C}$ for $30 \mathrm{~min}$. Slides were analyzed by Leica DMi6000 B inverted microscope (Leica Microsystems, Inc.) according to manufacturer's instruction and 3 fields per view were analyzed.

In vivo metastasis assay. Female athymic mice (Shanghai SLAC Laboratory Animal Co., Ltd.), 4-6 weeks of age, 18-22 g in weight were employed in the present study. A total of $5 \times 10^{6}$ MDA-MB-231 cells stably expressing scramble shRNA or shRNA-TAGLN2 were intravenously injected into mice via the tail vein ( 6 mice per group). At 6 weeks post-injection, mice in each group were sacrificed and the lungs were dissected for the analysis of metastasis.

In addition, $1 \times 10^{7}$ MDA-MB-231HM cells transfected with TAGLN2 or control vectors were injected into the mammary fat pad of mice (6 mice per group). The growth of tumors was monitored twice per week for $\sim 2$ weeks, when tumors were $1 \mathrm{~cm}^{3}$, the primary tumor was surgically removed under anesthesia. After 4 weeks, mice were sacrificed under anesthesia and the lungs were collected, fixed in $10 \%$ phosphate-buffered formalin solution for $12 \mathrm{~h}$ at room temperature and embedded in paraffin. Sections of the lungs were subjected to $\mathrm{H} \& \mathrm{E}$ staining for $3 \mathrm{~min}$ at room temperature; three slides per lung section were imaged under a light microscope (magnifications, $\mathrm{x} 10$ and 20). The presence of metastatic nodes in the lung were determined by two independent pathologists, who were blinded to the experimental conditions.

Statistical analysis. The results of at least three experiments are expressed as the mean \pm standard deviation. One-way ANOVA was used for comparisons between multiple groups and post hoc multiple comparisons were performed using Student-Newman-Keuls test. A Student's t-test was used for the test and control samples, respectively. A Fisher's exact test and a $\chi^{2}$ test were used to analyze categorical patient variables. $\mathrm{P}<0.05$ was considered to indicate a statistically significant difference. Statistical calculations were performed using STATA software version 14.0 (StataCorp LLC); statistical analysis of the clinicopathological factors was performed with GraphPad Prism 6.0 software (GraphPad Software, Inc.) and SPSS Software version 17.0 (SPSS, Inc.).

\section{Results}

TAGLN2 is a suppressor of metastasis in human breast cancer. TAGLN2 was downregulated in MDA-MB-231HM cells, which are a highly metastatic variant of the parental MDA-MB-231 cell line (7). To further understand the link between TAGLN2 and breast cancer metastasis, we analyzed the expression of TAGLN2 in 158 primary tumor samples from patients with breast cancer at the Fudan University Shanghai Cancer Center. Associations between TAGLN2 expression and the clinicopathological parameters of the breast cancer patients were summarized in Table III. The results revealed that no significant association was observed between TAGLN2 expression and age, histological type, tumor size, stage, and ER, PR or HER2 status. However, TAGLN2 expression was upregulated by $>4.9$-fold in the tumor specimens from lymph node-negative patients compared with that of lymph node-positive patients. Additionally, TAGLN2 expression was upregulated by 11.4-fold in the primary tumors of metastasis-negative patients compared with those exhibiting metastasis (Table III). These findings suggested that low levels of TAGLN2 were associated with the metastatic behavior in breast cancer.

Loss of TAGLN2 is associated with an aggressive tumor phenotype. The present study reported that downregulation of TAGLN2 was associated with breast cancer metastasis; thus, it was proposed that knockdown of TAGLN2 in breast cancer cells could promote cell invasion and metastasis. We established cell lines exhibiting stable TAGLN2 silencing from the parental MDA-MB-231 and BT-549 cell lines using the pLKO-shRNA vector (Fig. 1A). The following experiments were conducted with shRNA252 in MDA-MB-231 and shRNA377 in BT-549 cells. The results indicated that knockdown of TAGLN2 significantly promoted the invasive abilities of MDA-MB-231 and BT-549 cells compared with the corresponding control (Fig. 1B and C).

To further investigate the role of TAGLN2 in tumor metastasis in vivo, MDA-MB-231 cells that were stably depleted of TAGLN2 were injected into nude mice via the lateral tail vein. Histological analysis of the mice lungs revealed that knockdown of TAGLN2 could promote lung metastasis. The numbers and size of the lung nodules were significantly increased in the MDA-MB-231-shTAGLN2 group compared with that of the MDA-MB-231-scramble group (Fig. 1D). Collectively, the results of the present study suggest that TAGLN2 could be a negative regulator of breast cancer metastasis.

TAGLN2 directly interacts with PRDX1 and loss of TAGLN2 promotes ROS production. TAGLN2 has been reported as an actin-binding protein, and it may serve a role in regulating the cytoskeleton, which cooperatively functions in a variety of cellular processes and regulates the distribution of mitochondria (38). The present study revealed that mitochondria were sparsely distributed in TAGLN2-knockdown cells; however, no alterations in the morphology of F-actin were detected (Fig. 2A). To investigate the molecular mechanisms of TAGLN2 in breast cancer metastasis, we examined the proteins that interact with TAGLN2. TAGLN2 protein was immunoprecipitated from MDA-MB-231 lysates; the co-immunoprecipitated proteins were analyzed by MS, and the identified peptides were matched to protein databases to identify the parent proteins (Fig. 2B; Table IV). FLAG-tagged TAGLN2 vector was transfected in MDA-MB-231 cells and TAGLN2 was overexpressed; PRDX1 was determined to interact with TAGLN2 by immunoprecipitation analysis (Fig. 2C). In addition, the expression of PRDX1 was reduced in response to TAGLN2 silencing (Fig. 2D). We also downregulated TAGLN2 in MCF-7 cells (Fig. 2E).

Mitochondria are a major cellular source of ROS (39). PRDX1 is also involved in cellular ROS production (30). Flow cytometry was conducted to measure the levels of intracellular ROS following TAGLN2 downregulation (Fig. 2F). TAGLN2-depleted MDA-MB-231 and MCF-7 cells were stained with DCFDA; ROS production was then analyzed by 
Table III. Association between TAGLN2 expression and clinicopathologic parameters in breast cancer.

\begin{tabular}{|c|c|c|c|}
\hline Clinicopathological parameters & Number of cases & Median expression of TAGLN2 (normalized Cq) ${ }^{\mathrm{a}}$ & P-value \\
\hline Age, years & & & 0.676 \\
\hline$\leq 40$ & 26 & $10.158 \pm 3.124$ & \\
\hline$>40$ & 132 & $9.972 \pm 3.962$ & \\
\hline Histological type & & & 0.887 \\
\hline DCIS & 20 & $10.67 \pm 3.951$ & \\
\hline IDC & 138 & $9.973 \pm 3.542$ & \\
\hline TNM stage & & & 0.523 \\
\hline $\mathrm{I}+\mathrm{II}$ & 146 & $9.986 \pm 3.734$ & \\
\hline III & 12 & $9.831 \pm 3.894$ & \\
\hline Lymph node status & & & $<0.001$ \\
\hline Negative & 76 & $8.780 \pm 3.751$ & \\
\hline Positive & 82 & $11.081 \pm 3.926$ & \\
\hline Tumor size & & & 0.322 \\
\hline $\mathrm{T} 1+\mathrm{T} 2$ & 132 & $9.888 \pm 3.619$ & \\
\hline $\mathrm{T} 3+\mathrm{T} 4$ & 26 & $10.412 \pm 3.820$ & \\
\hline ER & & & 0.713 \\
\hline Negative & 61 & $9.875 \pm 3.756$ & \\
\hline Positive & 97 & $10.037 \pm 3.852$ & \\
\hline PR & & & 0.923 \\
\hline Negative & 66 & $9.891 \pm 3.762$ & \\
\hline Positive & 92 & $10.034 \pm 3.834$ & \\
\hline HER 2 & & & 0.874 \\
\hline Negative & 125 & $9.806 \pm 3.782$ & \\
\hline Positive & 33 & $10.613 \pm 3.696$ & \\
\hline Distant metastasis ${ }^{\mathrm{b}}$ & & & $<0.001$ \\
\hline Absent & 117 & $9.064 \pm 3.715$ & \\
\hline Present & 41 & $12.573 \pm 3.786$ & \\
\hline All cases & 158 & $9.974 \pm 3.770$ & \\
\hline
\end{tabular}

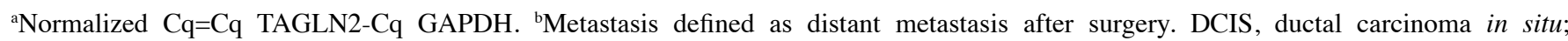
IDC, invasive ductal carcinoma; ER, estrogen receptor; PR, progesterone receptor; HER2, human epidermal growth factor receptor 2; TNM, tumor-node-metastasis; Based on Pearson $\chi^{2}$ test, for which P-vales are based on Fisher's exact test.

flow cytometry (40). ROS levels were significantly increased by 21 and $12 \%$ in MDA-MB-231 and MCF-7 cells following TAGLN2 knockdown, respectively, compared with the corresponding controls (Fig. 2F and G). These results suggest that downregulation of TAGLN2 induced the rearrangement of the mitochondria and the abnormal expression of PRDX1, by which several mechanisms underlying ROS production were induced.

Downregulation of TAGLN2 activates the NF- $\mathrm{B}$ pathway in breast cancer cell lines. ROS have been reported to promote cellular migration and invasion by activating downstream signaling, including the NF- $\mathrm{B}$ signaling pathway (41). Thus, we proposed that TAGLN2 knockdown could induce ROS production, activating the $\mathrm{NF}-\kappa \mathrm{B}$ signaling pathway. Therefore, a luciferase-reporter system was generated to monitor $\mathrm{NF}-\kappa \mathrm{B}$ activation. The luciferase activity within the reporter system increased in a dose-dependent manner following treatment with various concentrations of tumor necrosis factor- $\alpha$
(Fig. S1A). Furthermore, in cells transfected with the luciferase reporter vector and $\mathrm{NF}-\kappa \mathrm{B}$ transcription responsive elements (TREs) were treated with siRNA-TAGLN2 or scramble siRNA. As expected, cells with NF- $\kappa$ B TREs exhibited a 2.2-fold increase in luciferase expression in response to TAGLN2 knockdown (Fig. 3A). Western blot analysis was performed to examine $\mathrm{NF}-\kappa \mathrm{B}$ pathway activation. The results revealed that the expression levels of p50 and p65 were upregulated in MDA-MB-231 and MCF-7 cells transfected with shTAGLN2. Of note, I $\kappa$ B expression was suppressed following downregulation of TAGLN2 (Fig. 3B). In addition, the nuclear localization of p65 was analyzed, and served as a marker of activated NF- $\kappa$ B (Fig. S1B). In 10 human breast cancer cell lines, TAGLN2 expression was negatively correlated with the nuclear expression of p65 (Fig. S1C). Similar trends in the expression of p50 and p100 were observed in ZR-75-1, MCF-7, T47D, MDA-MB-231 and MDA-MB-468 cells (Fig. S1B and C). To further investigate the association 
A

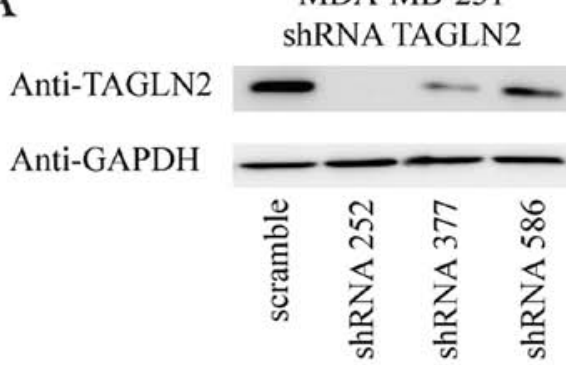

MDA-MB-231

ShRNA TAGLN2
BT549

shRNA TAGLN2

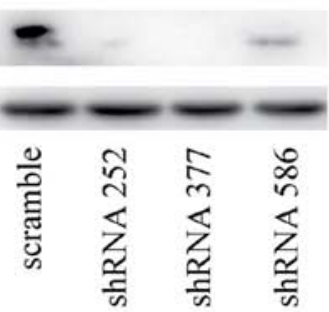

B

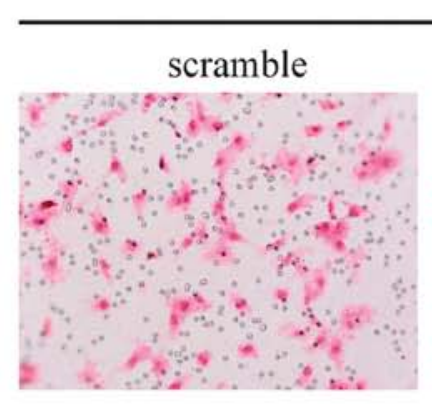

MDA-MB-231

C

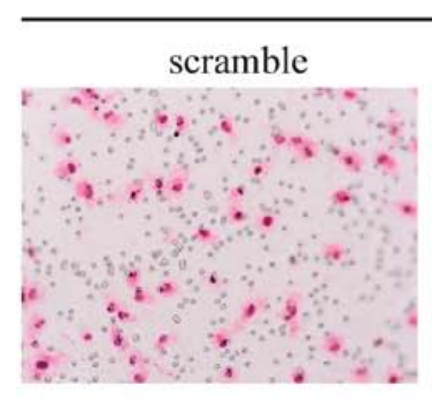

BT-549

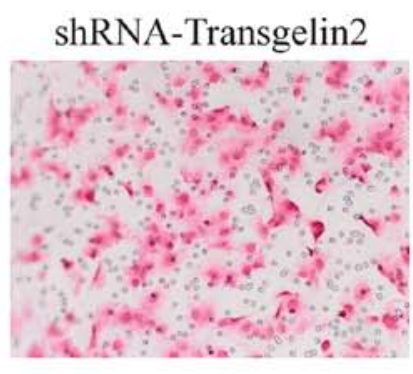

shRNA-Transgelin2

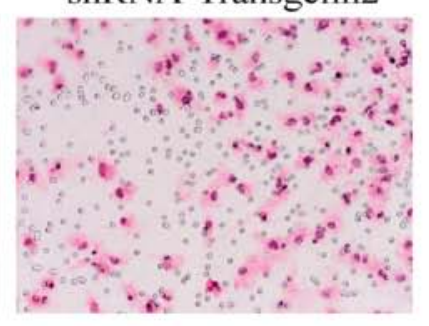

D
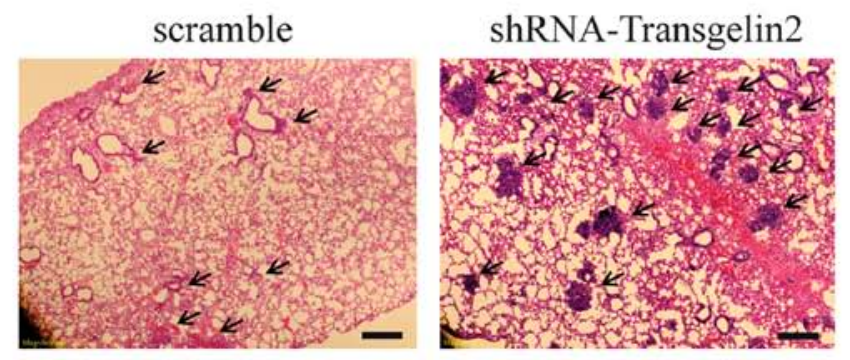
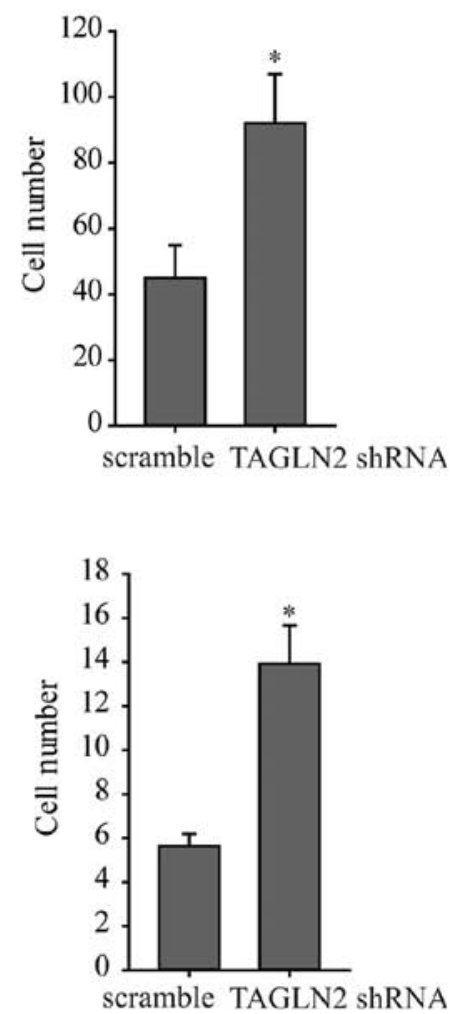

Figure 1. Loss of TAGLN2 promotes breast cancer cell invasion in vitro and metastasis in vivo. (A) Immunoblotting of TAGLN2 expression in MDA-MB-231 and BT549 cells transfected with TAGLN2 shRNA252, shRNA377, shRNA586 and scramble RNA. Data shown were representative of three independent experiments. Knockdown of TAGLN2 significantly promoted the invasion of (B) MDA-MB-231 and (C) BT-549 cell lines following transfection with pLKO.1-shRNA-TAGLN2 compared with cells transfected with scramble shRNA. Data were representative of three independent experiments. (D) Representative H\&E-stained sections of the lung tissues isolated from mice injected with MDA-MB-231 cells transfected with shRNA-TAGLN2 or shRNA-scramble via the lateral tail vein. The arrowhead indicated tumor formation in the lung. The number of metastatic nodules in the lung were counted and analyzed; $\mathrm{n}=6$ mice per group. Scale bar, $200 \mu \mathrm{m}$. ${ }^{*} \mathrm{P}<0.05$ vs. scramble. shRNA, short hairpin RNA; TAGLN2, transgelin 2.

between TAGLN2 and NF- $\mathrm{B}$ activation, MDA-MB-231 cells transfected with scramble or shTAGLN2 were treated with $18 \mu \mathrm{M}$ SN50, an NF- $\mathrm{NB}$ inhibitor, for $24 \mathrm{~h}$. Following inhibition of the $\mathrm{NF}-\kappa \mathrm{B}$ signaling pathway, the pro-migratory 
A

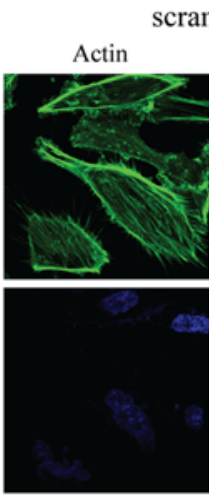

DAPI scramble

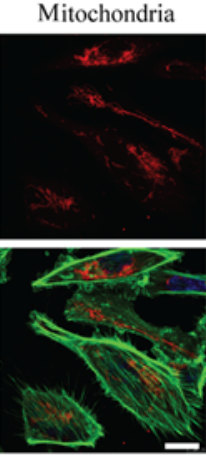

Merged

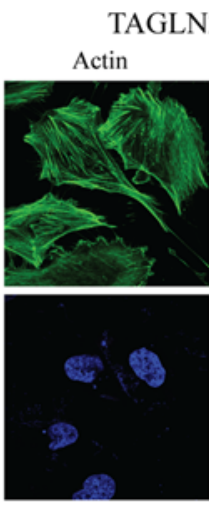

DAPI
AGLN2 shRNA

Mitochondria

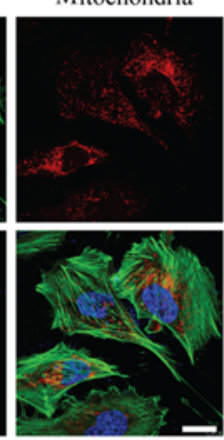

Merged
B

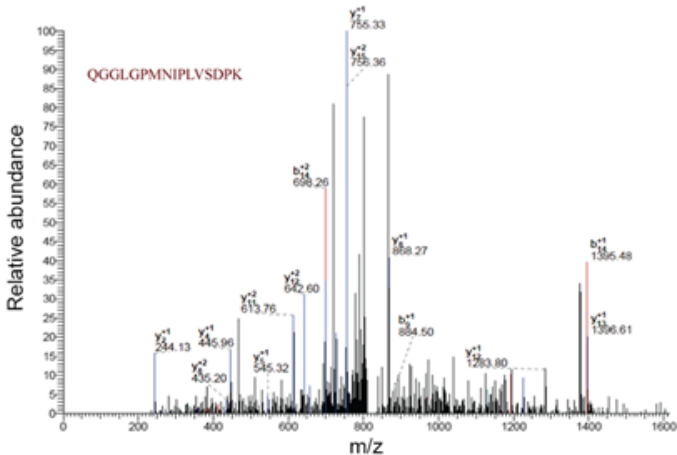

C

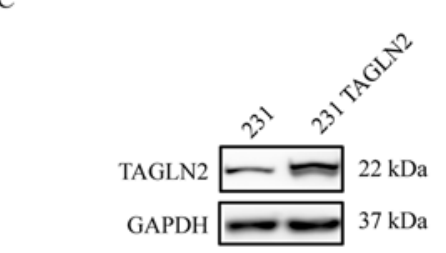

3XFLAG TAGLN2
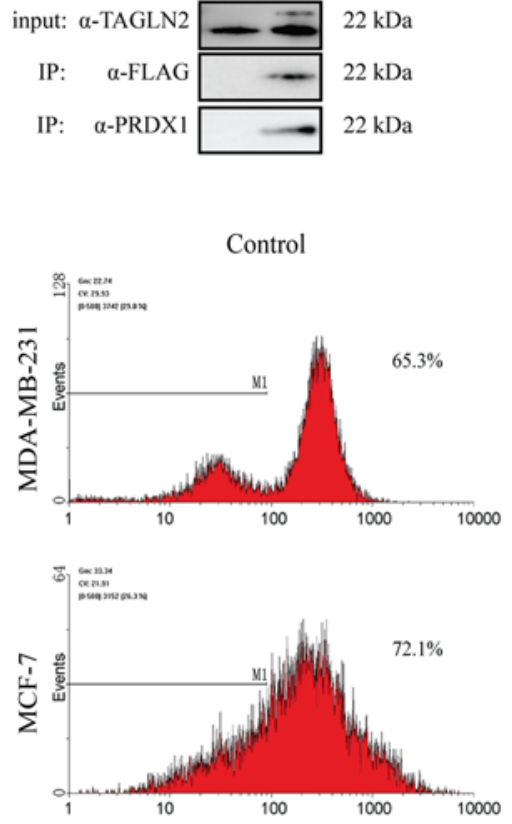

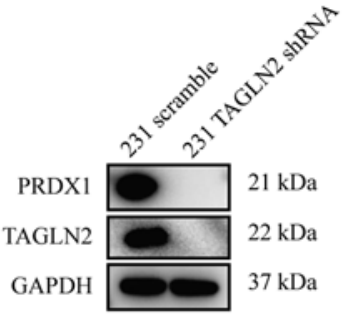

E

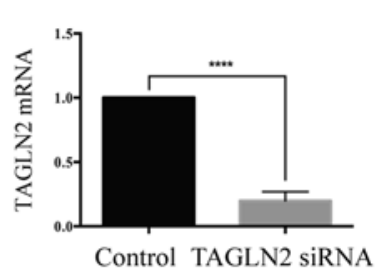

MCF-7

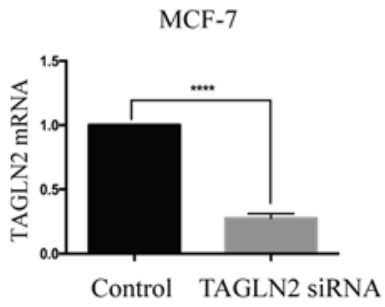

TAGLN2 siRNA
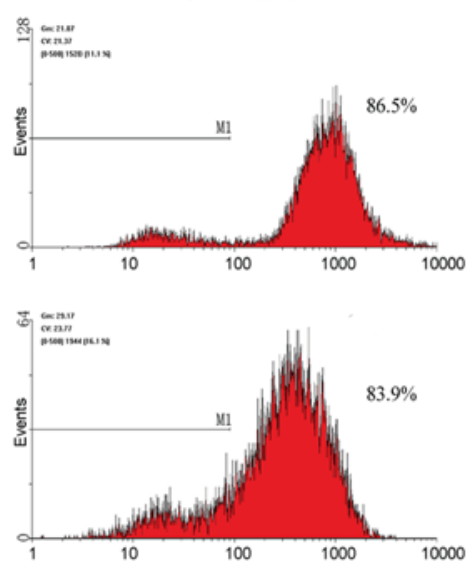

G

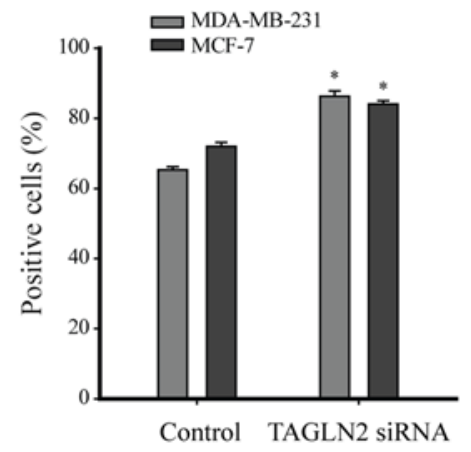

Figure 2. TAGLN2 promotes ROS production by interacting with PRDX1 and altering actin dynamics. (A) MDA-MB-231-scramble (left panel) and MDA-MB-231-shRNA-TAGLN2 (right panel) cells were stained for F-actin (green), mitochondria (red) and the nucleus (blue). Scale bar, $5 \mu \mathrm{m}$. (B) Liquid chromatography-MS analysis followed by MS/MS of immunoprecipitated FLAG-TAGLN2 from MDA-MB-231 cells revealed the interaction between PRDX1 and TAGLN2 in MDA-MB-231 cells. (C) Overexpression of TAGLN2, and co-immunoprecipitation of PRDX1 with TAGLN2. MDA-MB-231 cells were transfected with FLAG-tagged TAGLN2 and subjected to immunoprecipitation with anti-FLAG antibody followed by immunoblotting with antibodies. (D) Representative immunoblots of PRDX1 with TAGLN2 expression following TAGLN2 depletion in MDA-MB-231 cells. (E) The mRNA expression levels of TAGLN2 with TAGLN2 siRNA in MDA-MB-231 and MCF-7 cells. (F) Levels of ROS in MDA-MB-231 and MCF-7 cells treated with siRNA TAGLN2 as determined by flow cytometry, and presented as the fluorescence intensity of 2',7'-dichlorodihydrofluorescein diacetate. (G) The data were representative of five independent experiments. ${ }^{*} \mathrm{P}<0.05$ and ${ }^{* * * * *} \mathrm{P}<0.00005$ vs. control. MS, mass spectrometry; PRDX1, peroxiredoxin 1; ROS, reactive oxygen species; shRNA, short hairpin RNA; siRNA, small interfering RNA; TAGLN2, transgelin 2.

effects of TAGLN2 downregulation were reversed (Fig. 3C). These results supported the findings of the luciferase reporter assay and revealed that knockdown of TAGLN2 promoted the activation of NF- $\mathrm{kB}$ pathway in breast cancer cells.

Downregulation of TAGLN2 promotes microenvironmentassociated gene expression in breast cancer cells. The present study reported that knockdown of TAGLN2 promoted the formation of lung metastases by breast cancer cells. To determine the genes that were associated with the metastatic phenotype, RT-qPCR analysis of the microenvironment-associated genes was conducted, including genes involved in the immune and inflammatory responses, such as cell adhesion molecules, chemokines and 
Table IV. Parent proteins.

\begin{tabular}{|c|c|c|c|c|}
\hline Protein name (Uniprot ID) & MS-identified sequence & $\mathrm{MH}+$ & $\mathrm{z}$ & $\mathrm{m} / \mathrm{z}$ \\
\hline \multirow{7}{*}{$\begin{array}{l}\text { Transgelin-2 (TAGL2) } \\
\text { (P37802) }\end{array}$} & NFSDNQLQEGK & 1279.59 & 2 & 640.30 \\
\hline & TLM*NLGGLAVAR & 1231.68 & 2 & 616.35 \\
\hline & TLMNLGGLAVAR & 1215.69 & 2 & 608.35 \\
\hline & QM*EQISQFLQAAER & 1694.82 & 2 & 847.91 \\
\hline & DDGLFSGDPNWFPK & 1594.72 & 2 & 797.86 \\
\hline & QMEQISQFLQAAER & 1678.82 & 2 & 839.91 \\
\hline & YGINTTDIFQTVDLWEGK & 2100.03 & 2 & 1050.52 \\
\hline \multirow[t]{5}{*}{ Peroxiredoxin-1 (PRDX1) (Q06830) } & ATAVMPDGQFK & 1164.57 & 2 & 582.79 \\
\hline & QITVNDLPVGR & 1211.67 & 2 & 606.34 \\
\hline & QGGLGPM*NIPLVSDPK & 1638.85 & 2 & 819.93 \\
\hline & QGGLGPMNIPLVSDPK & 1622.86 & 2 & 811.93 \\
\hline & GLFIIDDKGILR & 1359.80 & 2 & 680.40 \\
\hline
\end{tabular}

M* represents the oxidized Met residue.
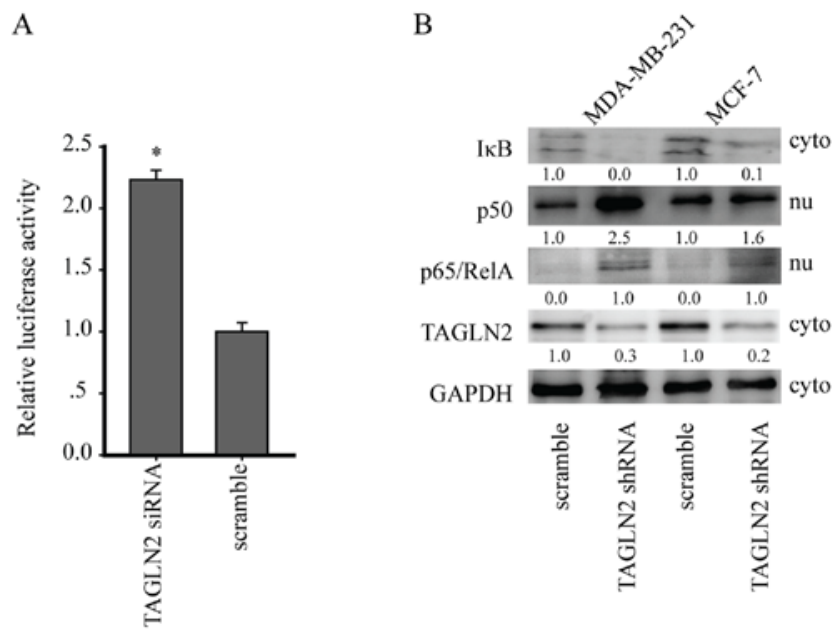

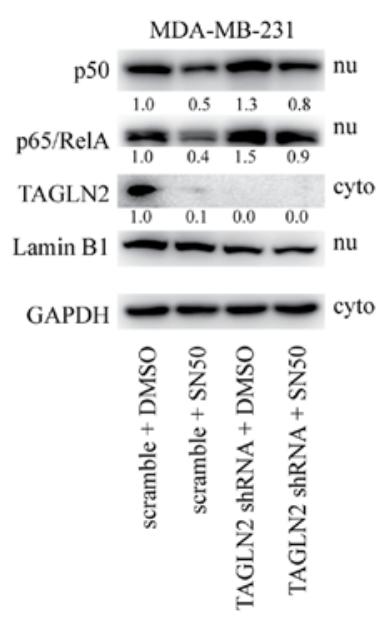

$\mathrm{C}$

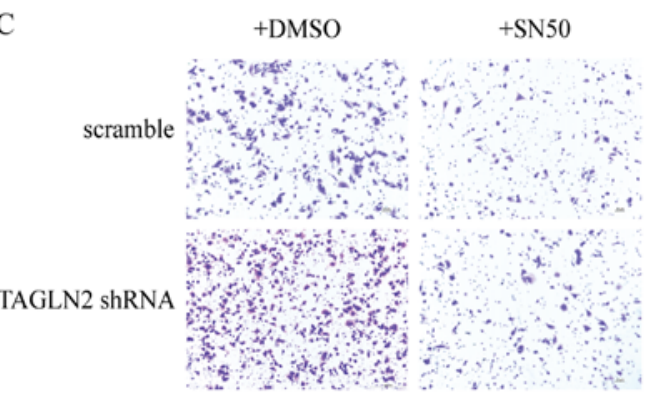

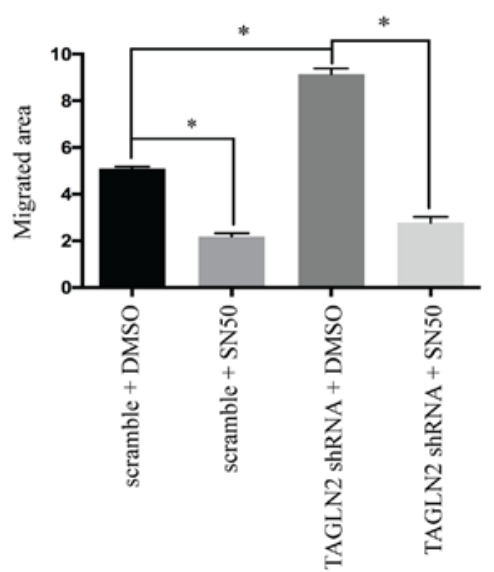

Figure 3. Loss of TAGLN2 expression induces NF- $\kappa$ B activation. (A) Luciferase activity of an NF- $\kappa$ B-luciferase reporter plasmid in TAGLN2-overexpressing $293 \mathrm{~T}$ cells was measured $48 \mathrm{~h}$ after stimulation with siRNA-TAGLN2 or scramble siRNA; luciferase activity was normalized to that of Renilla. Data were representative of three independent experiments. (B) Immunoblotting of IкB, p50, p65/RelA and TAGLN2 expression in MDA-MB-231 and MCF-7 cells transfected with pLKO.1-shRNA-TAGLN2 and pLKO.1-shRNA-scramble. The results of western blotting were representative of three independent experiments. (C) Cell migration was promoted in MDA-MB-231 cells transfected with pLKO.1-shRNA-TAGLN2 compared with cells treated with scramble shRNA. Treatment with $18 \mu \mathrm{M}$ SN50 for $24 \mathrm{~h}$ reversed the effects of TAGLN2 downregulation on cell invasion. Data are representative of three independent experiments. ${ }^{*}<0.05$ vs. scramble or as indicated. DMSO, dimethyl sulfoxide; NF- $\kappa$ B, nuclear factor- $\kappa \mathrm{B}$; shRNA, short hairpin RNA; siRNA, small interfering RNA; TAGLN2, transgelin 2 . 

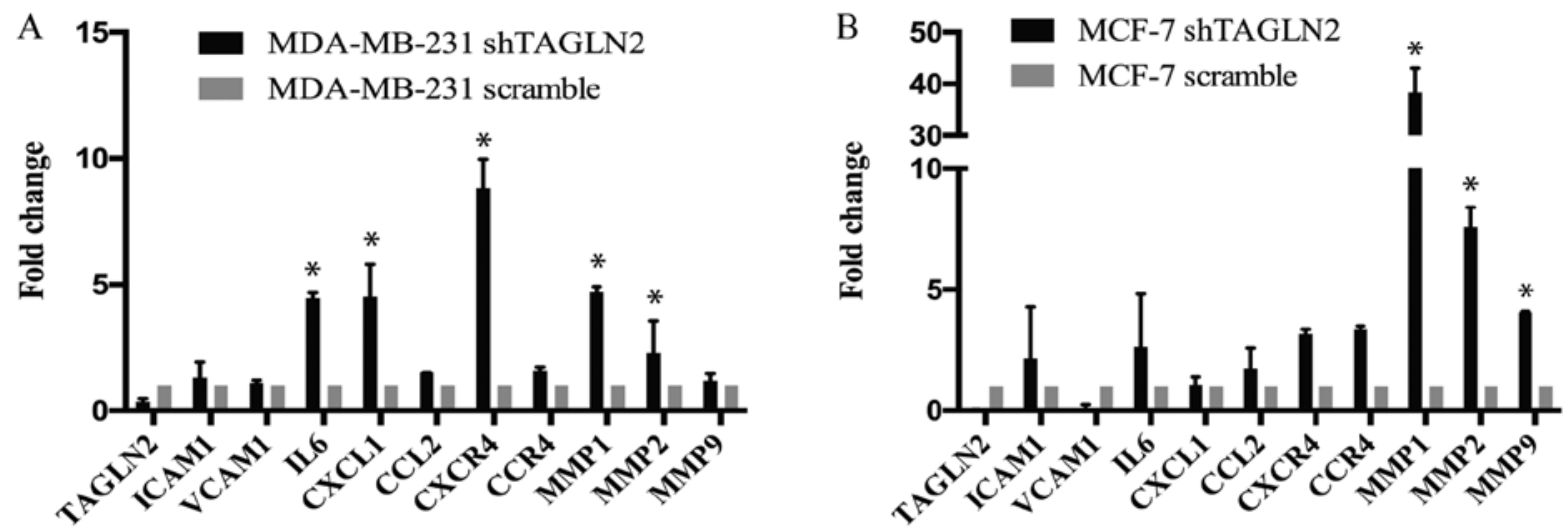

$\mathrm{C}$

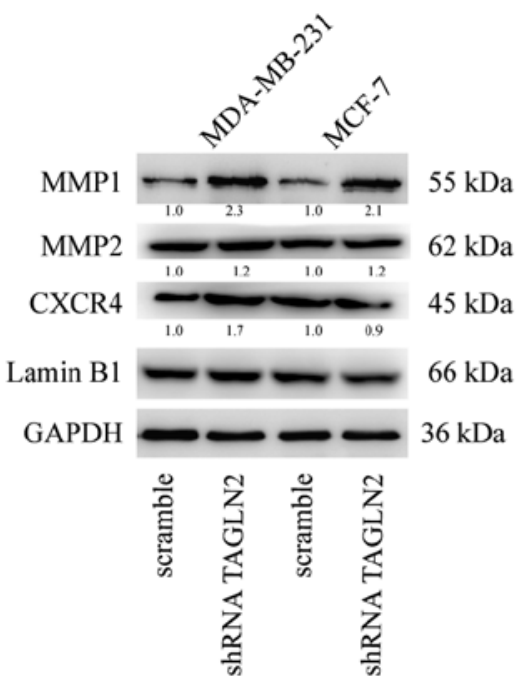

$\mathrm{D}$

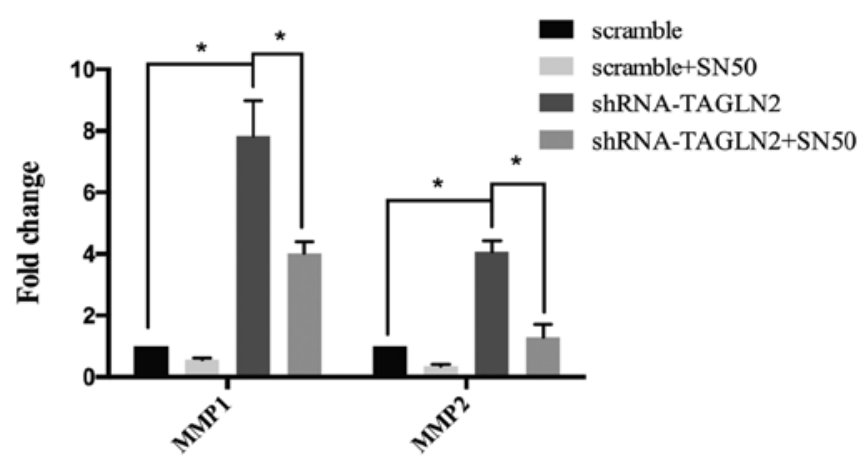

Figure 4. Analysis of metastasis-associated genes in TAGLN2-knockdown cancer cells. (A) RT-qPCR analysis of ICAM1, VCAM1, IL6, CXCL1, CCL2, CXCR4, CCR4, MMP1, MMP2, and MMP9 mRNA expression in MDA-MB-231 cells treated with scramble or shTAGLN2; results are presented relative to $\beta$-actin expression. Data shown was representative of three independent experiments. (B) RT-qPCR analysis of ICAM1, VCAM1, IL6, CXCL1, CCL2, CXCR4, CCR4, MMP1, MMP2 and MMP9 mRNA expression in MCF-7 cells treated with shControl or shTAGLN2; results are presented as relative to $\beta$-actin expression. Data are representative of three independent experiments. (C) Immunoblotting of CXCR4, MMP1 and MMP2 expression in MDA-MB-231 and MCF-7 cells treated with scramble or shTAGLN2. Western blots were representative of three independent experiments. (D) RT-qPCR analysis of MMP1 and MMP2 in MDA-MB-231 cells transfected with scramble or shTAGLN2 under treatment of DMSO or SN50 $(18 \mu \mathrm{M})$ for $24 \mathrm{~h}$. Data are representative of three independent experiments. " $\mathrm{P}<0.05$ vs. scramble or as indicated. CCL2, C-C motif chemokine ligand 2; CXCL1, C-X-C motif chemokine ligand 1; CCR4, C-C chemokine receptor type 4; CXCR4, including C-X-C chemokine receptor 4; DMSO, dimethyl sulfoxide; ICAM1, intercellular adhesion molecule 1; IL6, interleukin-6; MMP, matrix metalloproteinase; RT-qPCR, reverse transcription-quantitative polymerase chain reaction; shRNA, short hairpin RNA; TAGLN2, transgelin 2; VCAM1, vascular cell adhesion protein 1.

MMPs (42). The results indicated that interleukin-6, C-X-C motif chemokine ligand 1, CXCR4, MMP1 and MMP2 were significantly upregulated in MDA-MB-231 cells transfected with shTAGLN2 compared with the control (Fig. 4A). MMP1, MMP2 and MMP9 were significantly upregulated in MCF-7 cells following TAGLN2 knockdown compared with the control (Fig. 4B). Western blot analysis was performed to examine the expression of the metastasis-associated genes. In accordance with results of the RT-qPCR analysis, MMP1 and MMP2 were upregulated following downregulation of TAGLN2 in MDA-MB-231 and MCF-7 cells (Fig. 4C). Furthermore, MDA-MB-231 scramble and shTAGLN2-transfected cells were treated with SN50 to inhibit the $\mathrm{NF}-\kappa \mathrm{B}$ signaling pathway. The results demonstrated that the expression levels of MMP1 and MMP2 were downregulated in response to SN50 treatment compared with shTAGLN2 transfection alone (Fig. 4D). These findings suggested that downregulation of TAGLN2 promoted the expression of microenvironment-associated genes in breast cancer cells.

Overexpression of TAGLN2 suppresses in vivo breast cancer cell lung metastasis in a mouse model. To further examine the effects of TAGLN2 on host-tumor interactions in a mouse model, MDA-MB-231HM cells stably expressing the control or TAGLN2 overexpression vectors were injected into the mammary fat pad of athymic mice. Compared with the control group, the orthotropic transplantation of pCDH-CMV-TAGLN2-transfected MDA-MB-231HM cells resulted in fewer metastatic tubes in the lungs in vivo (Fig. 5A). Statistical analysis revealed a significant decrease in the number of metastatic tubes derived from the TAGLN2-overexpressing MDA-MB-231HM cells than of the control cells (Fig. 5B). Collectively, the findings of the present study suggested that overexpression of TAGLN2 suppressed breast cancer cell metastasis in a mouse model. 

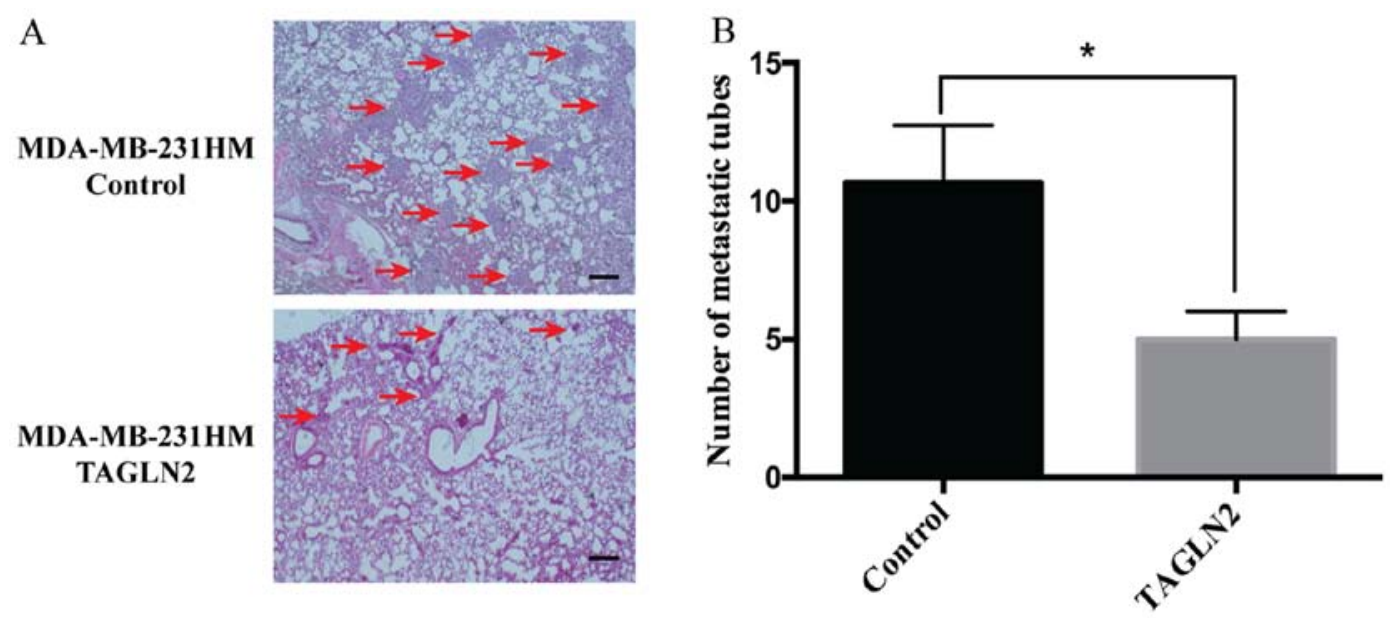

Figure 5. Overexpression of TAGLN2 suppresses in vivo lung metastasis in a mouse model. (A) Hematoxylin-eosin staining of lung tissues from mice injected with MDA-MB-231HM cells transfected with pCDH-CMV-TAGLN2 or control vector. The red arrows the lung tubes formed. Scale bar, $200 \mu \mathrm{m}$. (B) Number of metastatic lung tubes in mice injected with MDA-MB-231HM cells transfected with pCDH-CMV-TAGLN2 or control vector. $n=6$ mice per group. ${ }^{*} \mathrm{P}<0.05$. TAGLN2, transgelin 2 .

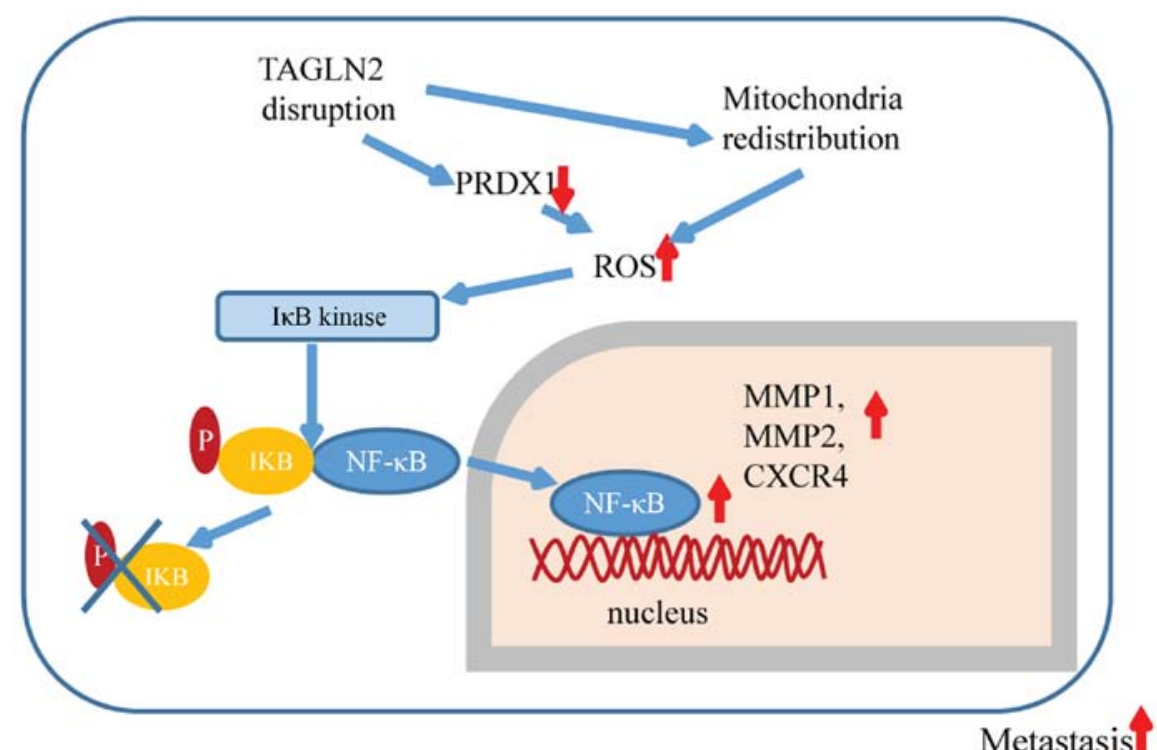

Figure 6. Schematic representation of the effects of TAGLN2 on breast cancer metastasis. CXCR4, including C-X-C chemokine receptor 4; MMP, matrix

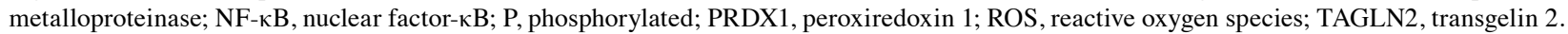

\section{Discussion}

In the present study, loss of TAGLN2 was reported to promote breast cancer cell invasion and metastasis by increasing intracellular ROS levels and activation of the NF- $\mathrm{\kappa B}$ signaling pathway. The effects of TAGLN2 may be mediated by its interaction with PRDX1 and the redistribution of the mitochondria (Fig. 6).

TAGLN, which contains a calponin-like domain, functions as a tumor suppressor $(43,44)$. Loss of TAGLN has been associated with the progression, differentiation and metastasis of colon cancer (18). TAGLN also inhibits tumor cell invasion via MMP9 suppression (45). Similar to TAGLN, TAGLN2 also belongs to the calponin family of proteins and may act as a tumor suppressor (14). Discrepancies in the functions of TAGLN2 have been reported previously. Upregulated TAGLN2 expression was associated with the development of gliomas (46), uterine cervical squamous carcinoma (47) and esophageal squamous carcinoma (48). On the contrary, Yoshida et al (17) reported that TAGLN2 was downregulated in metastatic tumors of the brain than in primary endometrial and ovarian cancers, suggesting TAGLN2 as a suppressor of metastasis. Zheng et al (49) revealed that knockdown of TAGLN2 improved the sensitivity of paclitaxel-resistant MCF-7 cells to paclitaxel treatment, and suppressed cellular migration and invasion; however, the mechanisms underlying the functions of TAGLN2 remain poorly understood. The results of the present study indicated that TAGLN2 was downregulated in metastasis-positive patients with breast cancer and MDA-MB-231HM cells. Therefore, TAGLN2 may be negatively associated with breast cancer metastasis. Depleted TAGLN2 expression by RNA interference could enhance the metastatic properties including invasion ability in vitro 
and promotion of lung metastasis in vivo of breast cancer cells. Xenograft models indicated that TAGLN2 inhibited the metastasis of breast cancer cells to the lungs. The findings of the present study suggest that TAGLN2 may serve as a suppressor of breast cancer metastasis.

Using LC/MS, we identified several TAGLN2-interacting proteins, including oxidation-regulation protein PRDX1, which has been reported to reduce the effects of ROS and regulate ROS-dependent signaling pathways $(32,50)$. Additionally, downregulation of TAGLN2 was proposed to reduce the expression of PRDX1 in the present study, which may partially contribute to increases in ROS levels. Alternatively, TAGLN2 may regulate ROS levels through the redistribution of the mitochondria. The dynamic actin cytoskeleton and specific actin-binding proteins are required for the regular and ordered transport of the mitochondria (51-53). The actin cytoskeleton is a key component involved in the regulation of intracellular ROS production (54-55). TAGLN2 associated with the cytoskeleton may serve as a sensor of environmental stress and participate in the modulation of certain signaling pathways. Consistent with this notion, TAGLN2 depletion may result in the redistribution of mitochondria and elevated ROS levels; increased ROS production in response to TAGLN2 depletion suggests that TAGLN2 may function as a suppressor of metastasis via signaling pathways mediated by ROS. Activation of the $\mathrm{NF}-\kappa \mathrm{B}$ pathway induces the expression of microenvironment-associated genes that promote the metastasis of breast cancer cells (56). The findings of the present study may provide insight as to how cytoskeletal proteins may actively affect cancer metastasis. Therefore, inducing the expression of TAGLN 2 could serve as a therapeutic strategy to suppress the expression of microenvironment-associated genes in various types of cancer.

Colonization is a critical, rate-limiting step of the metastatic cascade (57). The communication between tumor cells and surrounding cells serves an important role in colonization (58-59). CXCR4 is an important molecule involved in the spread and progression of breast cancer. Increased CXCR4 expression serves as an indicator of poor prognosis in patients with breast cancer. MMPs are crucial for the development of healthy tissue architecture, and serve critical roles in numerous physiological and pathological processes. Similar to CXCR4, MMPs also play key roles in tumor invasion and the induction of metastasis. The expression of MMPs has also been associated with the poor prognosis of patients with breast cancer (60). Our findings demonstrated that loss of TAGLN2 induces CXCR4, MMP1 and MMP2 expression, and promotes cancer metastasis. Additionally, TAGLN2 expression was associated with lymph node metastasis and distant metastasis, which are important prognostic factors in breast cancer patients. However, the clinical significance of TAGLN2 requires further investigation, in particular the outcomes of breast cancer patients of the same age, gender, ER/PR/HER-2 status, receiving similar treatment, and varying expression levels of TAGLN2, which we aim to study in the future. In addition, our in vivo analysis of lung metastasis for comparing MDA-MB-231 cells with TAGLN2 low/high-expression with the control cells may provide further insight into the role of TAGLN2 in the present study.

In summary, we identified TAGLN2 as a tumor suppressor associated with breast cancer metastasis, in which its effects could be mediated by redox signaling, and may be a novel role for TAGLN2 in the regulation of cancer cell metastasis. Therefore, TAGLN2 may be considered as a critical regulator of the ROS/NF- $\kappa \mathrm{B}$ pathway in breast cancer.

\section{Acknowledgements}

The authors would like to thank Dr Yin Chen and colleagues at the Shanghai Institute of Materia Medica, Chinese Academy of Science for their excellent guidance in the animal experiments. The authors would also like to thank Dr Dongyin Guan and Dr Dan Liu from Shanghai InnoStar Bio-Tech Co. Ltd. for their critical analysis of the manuscript.

\section{Funding}

The present study was supported by grants from the National Natural Science Foundation of China (grant nos. 81302303 and 81502293). The funders had no role in study design, data collection and analysis, decision to publish or preparation of the manuscript.

\section{Availability of data and materials}

The datasets used and/or analyzed during the current study are available from the corresponding author on reasonable request.

\section{Authors' contributions}

GHD, SJY, JW and ZMS made substantial contributions to the conception and design of the present study. LY, QH and SJY conducted the majority of the experiments. SGX and XYK assisted in the acquisition of data, including patient management. LY, QH and GYL assisted with the analysis and interpretation of data. SJY and JW wrote, reviewed and revised the manuscript. GHD and ZMS supervised the research. All authors participated in final approval of the version to be published and contributed to ensuing that questions related to the accuracy or integrity of any part of the work are appropriately investigated and resolved.

\section{Ethics approval and consent to participate}

The study was approved by the Ethics Committee of the Fudan University Shanghai Cancer Center. All patients provided written informed consent.

\section{Patient consent for publication}

Not applicable.

\section{Competing interests}

The authors declare that they have no competing interests.

\section{References}

1. Berry DA, Cronin KA, Plevritis SK, Fryback DG, Clarke L, Zelen M, Mandelblatt JS, Yakovlev AY, Habbema JD and Feuer EJ; Cancer Intervention and Surveillance Modeling Network (CISNET) Collaborators: Effect of screening and adjuvant therapy on mortality from breast cancer. N Engl J Med 353: 1784-1792, 2005. 
2. Chen W, Zheng R, Baade PD, Zhang S, Zeng H, Bray F, Jemal A, Yu XQ and He J: Cancer statistics in China, 2015. CA Cancer J Clin 66: 115-132, 2016.

3. Chaffer CL and Weinberg RA: A perspective on cancer cell metastasis. Science 331: 1559-1564, 2011

4. Eccles SA and Welch DR: Metastasis: Recent discoveries and novel treatment strategies. Lancet 369: 1742-1757, 2007.

5. Lambert AW, Pattabiraman DR and Weinberg RA: Emerging biological principles of metastasis. Cell 168: 670-691, 2017.

6. Geiger T, Madden SF, Gallagher WM, Cox J and Mann M: Proteomic portrait of human breast cancer progression identifies novel prognostic markers. Cancer Res 72: 2428-2439, 2012.

7. Xu SG, Yan PJ and Shao ZM: Differential proteomic analysis of a highly metastatic variant of human breast cancer cells using two-dimensional differential gel electrophoresis. J Cancer Res Clin Oncol 136: 1545-1556, 2010.

8. Bertucci F, Birnbaum D and Goncalves A: Proteomics of breast cancer: Principles and potential clinical applications. Mol Cell Proteomics 5: 1772-1786, 2006.

9. Murugaesu N, Iravani M, van Weverwijk A, Ivetic A, Johnson DA, Antonopoulos A, Fearns A, Jamal-Hanjani M, Sims D, Fenwick K, et al: An in vivo functional screen identifies ST6GalNAc2 sialyltransferase as a breast cancer metastasis suppressor. Cancer Discov 4: 304-317, 2014.

10. Ooms LM, Binge LC, Davies EM, Rahman P, Conway JR Gurung R, Ferguson DT, Papa A, Fedele CG, Vieusseux JL, et al The inositol polyphosphate 5-phosphatase PIPP regulates AKT1-dependent breast cancer growth and metastasis. Cancer Cell 28: 155-169, 2015.

11. Okita Y, Kimura M, Xie R, Chen C, Shen LT, Kojima Y, Suzuki H, Muratani M, Saitoh M, Semba K, et al: The transcription factor MAFK induces EMT and malignant progression of triple-negative breast cancer cells through its target GPNMB. Sci Signal 10: pii: eaak9397, 2017

12. Stanier P, Abu-Hayyeh S, Murdoch JN, Eddleston J and Copp AJ Paralogous sm22alpha (Tagln) genes map to mouse chromosomes 1 and 9: Further evidence for a paralogous relationship. Genomics 51: 144-147, 1998

13. Li M, Li S, Lou Z, Liao X, Zhao X, Meng Z, Bartlam M and Rao Z: Crystal structure of human transgelin. J Struct Biol 162: 229-236, 2008.

14. Shapland C, Hsuan JJ, Totty NF and Lawson D: Purification and properties of transgelin: A transformation and shape change sensitive actin-gelling protein. J Cell Biol 121: 1065-1073, 1993.

15. Elsner M, Rauser S, Maier S, Schöne C, Balluff B, Meding S, Jung G, Nipp M, Sarioglu H, Maccarrone G, et al: MALDI imaging mass spectrometry reveals COX7A2, TAGLN2 and S100-A10 as novel prognostic markers in Barrett's adenocarcinoma. J Proteomics 75: 4693-4704, 2012.

16. Leung WK, Ching AK, Chan AW, Poon TC, Mian H, Wong AS To KF and Wong N: A novel interplay between oncogenic PFTK1 protein kinase and tumor suppressor TAGLN2 in the control of liver cancer cell motility. Oncogene 30: 4464-4475, 2011.

17. Yoshida A, Okamoto N, Tozawa-Ono A, Koizumi H, Kiguchi K, Ishizuka B, Kumai T and Suzuki N: Proteomic analysis of differential protein expression by brain metastases of gynecological malignancies. Human Cell 26: 56-66, 2013.

18. Shields JM, Rogers-Graham K and Der CJ: Loss of transgelin in breast and colon tumors and in RIE-1 cells by Ras deregulation of gene expression through Raf-independent pathways. J Biol Chem 277: 9790-9799, 2002

19. Luanpitpong S, Talbott SJ, Rojanasakul Y, Nimmannit U, Pongrakhananon V, Wang L and Chanvorachote P: Regulation of lung cancer cell migration and invasion by reactive oxygen species and caveolin-1. J Biol Chem 285: 38832-38840, 2010

20. Zheng Y, Miyamoto DT, Wittner BS, Sullivan JP, Aceto N, Jordan NV, Yu M, Karabacak NM, Comaills V, Morris R, et al: Expression of $\beta$-globin by cancer cells promotes cell survival during blood-borne dissemination. Nat Commun 8: 14344, 2017.

21. Zhou G, Peng F, Zhong Y, Chen Y, Tang M and Li D: Rhein suppresses matrix metalloproteinase production by regulating the Rac1/ROS/MAPK/AP-1 pathway in human ovarian carcinoma cells. Int J Oncol 50: 933-941, 2017.

22. Chen B, Liu J, Ho TT, Ding X and Mo YY: ERK-mediated NF- $\kappa B$ activation through ASIC1 in response to acidosis. Oncogenesis 5: e279, 2016.

23. Cao L, Chen X, Xiao X, Ma Q and Li W: Resveratrol inhibits hyperglycemia-driven ROS-induced invasion and migration of pancreatic cancer cells via suppression of the ERK and p38 MAPK signaling pathways. Int J Oncol 49: 735-743, 2016.
24. Księżakowska-ŁakomaK,Żyła MandWilczyński JR: Mitochondrial dysfunction in cancer. Prz Menopauzalny 13: 136-144, 2014.

25. Morgan MJ and Liu ZG: Crosstalk of reactive oxygen species and NF- $\kappa \mathrm{B}$ signaling. Cell Res 21: 103-115, 2011.

26. Vasquez-Dunddel D, Pan F, Zeng Q, Gorbounov M, Albesiano E, Fu J, Blosser RL, Tam AJ, Bruno T, Zhang H, et al: STAT3 regulates arginase-I in myeloid-derived suppressor cells from cancer patients. J Clin Invest 123: 1580-1589, 2013.

27. Yang CS, Kim JJ, Lee SJ, Hwang JH, Lee CH, Lee MS and Jo EK: TLR3-triggered reactive oxygen species contribute to inflammatory responses by activating signal transducer and activator of transcription-1. J Immunol 190: 6368-6377, 2013.

28. Yoon S, Woo SU, Kang JH, Kim K, Kwon MH, Park S, Shin HJ, Gwak HS and Chwae YJ: STAT3 transcriptional factor activated by reactive oxygen species induces IL6 in starvation-induced autophagy of cancer cells. Autophagy 6: 1125-1138, 2010.

29. Zhang Q, Raje V, Yakovlev VA, Yacoub A, Szczepanek K, Meier J, Derecka M, Chen Q, Hu Y, Sisler J, et al: Mitochondrial-localized Stat3 promotes breast cancer growth via phosphorylation of serine 727. J Biol Chem 288: 31280-31288, 2013.

30. Egler RA, Fernandes E, Rothermund K, Sereika S, de SouzaPinto N, Jaruga P, Dizdaroglu M and Prochownik EV: Regulation of reactive oxygen species, DNA damage and c-Myc function by peroxiredoxin 1. Oncogene 24: 8038-8050, 2005

31. Lv WP, Li MX and Wang L: Peroxiredoxin 1 inhibits lipopolysaccharide-induced oxidative stress in lung tissue by regulating P38/JNK signaling pathway. Eur Rev Med Pharmacol Sci 21: 1876-1883, 2017.

32. Ding C, Fan X and Wu G: Peroxiredoxin 1-an antioxidant enzyme in cancer. J Cell Mol Med 21: 193-202, 2017.

33. Wang $J$, Lin $\mathrm{D}$, Peng $\mathrm{H}$, Huang $\mathrm{Y}$, Huang $\mathrm{J}$ and $\mathrm{Gu} \mathrm{J}$ : Cancer-derived immunoglobulin $\mathrm{G}$ promotes tumor cell growth and proliferation through inducing production of reactive oxygen species. Cell Death Dis 4: e945, 2013.

34. Cao J, Schulte J, Knight A, Leslie NR, Zagozdzon A, Bronson R, Manevich Y, Beeson C and Neumann CA: Prdx1 inhibits tumorigenesis via regulating PTEN/AKT activity. EMBO J 28: 1505-1517, 2009.

35. Singletary SE and Connolly JL: Breast cancer staging: Working with the sixth edition of the AJCC Cancer Staging Manual. CA Cancer J Clin 56: 37-47; quiz 50-1, 2006.

36. Lundgren DH, Han DK and Eng JK: Protein identification using TurboSEQUEST. Curr Protoc Bioinformatics Chapter 13: Unit 13.3, 2005.

37. Livak KJ and Schmittgen TD: Analysis of relative gene expression data using real-time quantitative PCR and the 2(-Delta Delta C(T)) method. Methods 25: 402-408, 2001

38. Meng T, Liu L, Hao R, Chen S and Dong Y: Transgelin-2: A potential oncogenic factor. Tumour Biol 39: 1010428317702650, 2017.

39. Collins Y, Chouchani ET, James AM, Menger KE, Cochemé HM and Murphy MP: Mitochondrial redox signalling at a glance. J Cell Sci 125: 801-806, 2012.

40. Eruslanov E and Kusmartsev S: Identification of ROS using oxidized DCFDA and flow-cytometry. Methods Mol Biol 594: 57-72, 2010.

41. Wang F, Yang JL, Yu KK, Xu M, Xu YZ, Chen L, Lu YM, Fang HS, Wang XY, Hu ZQ, et al: Activation of the NF- $\kappa B$ pathway as a mechanism of alcohol enhanced progression and metastasis of human hepatocellular carcinoma. Mol Cancer 14: 10, 2015.

42. Lu H, Ouyang W and Huang C: Inflammation, a key event in cancer development. Mol Cancer Res 4: 221-233, 2006.

43. Assinder SJ, Stanton JA and Prasad PD: Transgelin: An actin-binding protein and tumour suppressor. Int J Biochem Cell Biol 41: 482-486, 2009.

44. Yang Z, Chang YJ, Miyamoto H, Ni J, Niu Y, Chen Z, Chen YL, Yao JL, di Sant'Agnese PA and Chang C: Transgelin functions as a suppressor via inhibition of ARA54-enhanced androgen receptor transactivation and prostate cancer cell growth. Mol Endocrinol 21: 343-358, 2007.

45. Nair RR, Solway J and Boyd DD: Expression cloning identifies transgelin (SM22) as a Novel repressor of 92-kDa type IV collagenase (MMP-9) expression. J Biol Chem 281: 26424-26436, 2006.

46. Han MZ, Xu R, Xu YY, Zhang X, Ni SL, Huang B, Chen AJ, Wei YZ, Wang S, Li WJ, et al: TAGLN2 is a candidate prognostic biomarker promoting tumorigenesis in human gliomas. J Exp Clin Cancer Res 36: 155, 2017.

47. Yakabe K, Murakami A, Kajimura T, Nishimoto Y, Sueoka K, Sato S, Nawata S and Sugino N: Functional significance of transgelin-2 in uterine cervical squamous cell carcinoma. J Obstet Gynaecol Res 42: 566-572, 2016. 
48. Du YY, Zhao LM, Chen L, Sang MX, Li J, Ma M and Liu JF: The tumor-suppressive function of miR-1 by targeting LASP1 and TAGLN2 in esophageal squamous cell carcinoma. J Gastroenterol Hepatol 31: 384-393, 2016.

49. Zheng X, Chen S, Yang Q, Cai J, Zhang W, You H, Xing J and Dong Y: Salvianolic acid A reverses the paclitaxel resistance and inhibits the migration and invasion abilities of human breast cancer cells by inactivating transgelin 2. Cancer Biol Ther 16 : $1407-1414,2015$

50. Ahmed W and Lingner J: PRDX1 and MTH1 cooperate to prevent ROS-mediated inhibition of telomerase. Genes Dev 32: 658-669, 2018.

51. Boldogh IR and Pon LA: Interactions of mitochondria with the actin cytoskeleton. Biochim Biophys Acta 1763: 450-462, 2006.

52. Rappaport L, Oliviero P and Samuel JL: Cytoskeleton and mitochondrial morphology and function. Mol Cell Biochem 184: 101-105, 1998.

53. Moore AS, Wong YC, Simpson CL and Holzbaur EL: Dynamic actin cycling through mitochondrial subpopulations locally regulates the fission-fusion balance within mitochondrial networks Nat Commun 7: 12886, 2016.

54. Breitenbach M, Laun P and Gimona M: The actin cytoskeleton, RAS-cAMP signaling and mitochondrial ROS in yeast apoptosis. Trends Cell Biol 15: 637-639, 2005.
55. Bhat SS, Parray AA, Mushtaq U, Fazili KM and Khanday FA: Actin depolymerization mediated loss of SNTA1 phosphorylation and Racl activity has implications on ROS production, cell migration and apoptosis. Apoptosis 21: 737-748, 2016.

56. Roy P, Sarkar UA and Basak S: The NF- $\kappa$ B activating pathways in multiple myeloma. Biomedicines 6: E59, 2018.

57. Klein CA: Cancer. The metastasis cascade. Science 321: 1785-1787, 2008

58. Shahriari K, Shen F, Worrede-Mahdi A, Liu Q, Gong Y, Garcia FU and Fatatis A: Cooperation among heterogeneous prostate cancer cells in the bone metastatic niche. Oncogene 36: 2846-2856, 2017.

59. Shibue T, Brooks MW and Weinberg RA: An integrin-linked machinery of cytoskeletal regulation that enables experimental tumor initiation and metastatic colonization. Cancer Cell 24: 481-498, 2013.

60. Zhang J, Chen J, Wo D, Yan H,Liu P, Ma E, Li L, Zheng L, Chen D, Yu Z, et al: LRP6 ectodomain prevents SDF-1/CXCR4-induced breast cancer metastasis to lung. Clin Cancer Res 25: 4832-4845, 2019.

This work is licensed under a Creative Commons Attribution-NonCommercial-NoDerivatives 4.0 International (CC BY-NC-ND 4.0) License. 